\title{
Efficiency and Outcome of Healing Practices Performed by Spirit Dancers in Healing Mental Illness - A Patient's Perspective
}

\author{
Prakasha Amin ${ }^{1}$, Mohan A.K² \\ 1, 2 Department of Social Work, Central University of Kerala, India.
}

\section{ABSTRACT}

\section{BACKGROUND}

In many rural communities, the cause of mental illness is attributed to black magic, spirit possession of past sin and the coastal region of Karnataka is not exempted from it. The natives of this region ascribe the cause of mental illness to the spirit or demigod, and they seek the help of traditional healers such as spirit dancers for the recovery. This help-seeking behaviour of the people results in delay in seeking psychiatry care and affects the recovery of the person with mental health problems. Therefore, this study explores the opinion of clients undergone traditional healing for mental health problems and the results of the study could contribute to planning an appropriate health promotion activity to promote community mental health.

\section{METHODS}

The present study was explorative, undertaken in the Udupi district of Karnataka state, which explores the views of the respondents about the cause of mental health problem and the outcome of traditional healing for their problems. Altogether 200 clients visiting traditional healers for mental health care were interviewed based on the snowball sampling technique and the interview schedule was used as a tool to gather the data.

\section{RESULTS}

Of the 200 respondents interviewed, 27.5 percent were adults ( 31 to 40 years), while 43.1 percent were unemployed. Black magic was found to be the major cause for mental health problems among 25.5 percent of the respondents; whereas, 26 percent of the respondents felt recovered completely after undergoing traditional healing for mental health problems.

\section{CONCLUSIONS}

The recognition of mental health problems is very much essential for people with mental health problems to seek professional help. This could help mental health professionals to diagnose illness at the very beginning and provide better mental health care. However, the explanatory model of the patients needs to be taken into consideration while providing modern medical care.

\section{KEY WORDS}

Black Magic, Mental Illness, Serpent Worship, Spirt Dancer, Traditional Healers
Corresponding Author: Dr. Mohan A.K, Dean, School of Social Sciences, HOD and Associate Professor, Department of Social Work, Central University of Kerala, Kerala, India.

E-mail:mohanak@cukerala.ac.in

DOI: $10.14260 /$ jemds/2021/172

How to Cite This Article:

Amin P, Mohan AK. Efficiency and outcome of healing practices performed by spirit dancers in healing mental illness - a patient's perspective. J Evolution Med Dent Sci 2021;10(11):803-808, DOI: $10.14260 /$ jemds/2021/172

Submission 22-09-2020,

Peer Review 21-01-2021,

Acceptance 28-01-2021,

Published 15-03-2021.

Copyright (C) 2021 Prakasha Amin et al. This is an open access article distributed under Creative Commons Attribution License [Attribution 4.0 International (CC BY 4.0)] 


\section{BACKGROUND}

Mental health is a major concern of India where about 14 percent of the global burden of disease attributed to neuropsychiatric disorders and progress in mental health service delivery has been slow. ${ }^{1}$ The total prevalence of mental disorders in India is 58 per 1000 people, 48.9 per 1000 in the rural and 80.6 per 1000 in the urban population, while the prevalence of major mental and behavioural disorders at any given point of time is $65 / 1000$ population. $^{2}$ The survey conducted in 2016 in Karnataka found that 3,617 women were suffering from neurological disorders whereas, 2,657 men found similar problems. 2,190 people of the urban area had a minor mental illness, whereas, it was higher compared to a rural area $(4,070)$. The prevalence of schizophrenia, mood disorders, and neurotic or stress-related disorders was very much higher, and this scenario could be due to fast-paced lifestyles, stress, complexities of living, a breakdown of support systems and challenges of economic instability. ${ }^{3}$ The report ${ }^{4}$ indicates that, almost, 197.3 million people had mental disorders in India in the year 2017, while 45.7 million people suffered from depressive disorders and 44.9 million (41.2 48.9) with anxiety disorders. Apart from depression and anxiety intellectual disability (10.8 percent), schizophrenia (9.8 percent), bipolar disorder (6.9 percent), conduct disorder (5.9 percent), autism spectrum disorders (3.2 percent), eating disorders (2.2 percent) and attention-deficit hyperactivity disorder ( 0.3 percent) contributed the most for the total mental disorders disability-adjusted life year (DALYs). As per the Global Burden of Disease report, in India 2, 30,314 suicide death cases were reported in 2016, the age-standardised rates per one lakh population being 21.2 men and 14.7 women. In eight Indian States, the suicide rate was above 24 per one lakh population and in 6 of these States, the female suicide rate exceeded 18 per one lakh. The teenagers' age group between 13 and 17 years is the most vulnerable to suicide while 10.6 per lakh population is at suicidal risk which is low in Chhattisgarh (2.9 percent) and high in Kerala (12.6 percent). ${ }^{5}$

\section{Mental Health Resource in India}

Over the past two decades, India's economic development has coincided with critical improvements in life span, literacy, and income. Despite these developments, still in rural India, significant challenges remain in infrastructure and access to quality medical care. ${ }^{6}$ The National Health Policy 2017 aims to double the government spend from the existing 1.15 percent of the gross domestic product (GDP) to 2.5 percent by 2025 , in 2018 - 2019 the budgetary allocation of Rs. 52,800 crores for health was merely 5 percent higher than the revised estimate of Rs. 51550.85 crore, in 2017 / 18. However, this fund is not enough to cater to the mental health care needs of 13.7 percent of the population. According to the World Health Organization (WHO's) Mental Health Atlas, the Indian government's total expenditure on mental health as a percentage of total government health expenditure was 1.3 percent which is very less compared to other developing countries. ${ }^{7}$

Despite prior and current efforts in enhancing mental health care delivery across the country, there is, a huge treatment gap still exists for all types of mental health problems in India. The National Mental Health Survey reports indicate that, overall treatment gap of 83 percent among which the treatment gap for common mental disorders is 85 percent which is higher compared to the severe mental disorders (73.6 percent). ${ }^{8}$ The report of the World Health Organization reveals that 75 percent of the health infrastructure, medical manpower, and other health resources are concentrated in urban areas where only 27 percent of the population lives in the urban area. ${ }^{9}$ As per the available report, approximately 60,000 beds are available to provide psychiatry care for mentally ill patients where availability of the psychiatrists (9000), psychiatric nurses (2000), psychiatric social workers (1000) and psychologists (1000) is very less to cater the needs of mentally ill. ${ }^{10}$ It is also important to understand that, cultural belief and the easy accessibility of traditional healing resources are important reasons for not seeking medical care among people suffering from mental health problems in India.

\section{Stigma Associated with Mental Illness}

Access to sufficient mental health care always falls short of both implicit and explicit needs in India. It is mainly because mental illness is still not well understood, often ignored, and considered a taboo. The people suffering from mental health problems, their families and relatives, as well as professionals providing specialised care, are still the object of marked stigmatisation. The concept of mental health problems is often associated with fear of the threat of patients with such illnesses. The result of all these can affect the patient's physical health needs. ${ }^{11}$

People with mental health problems suffer on two fronts; first, debilitating symptoms that may impede their mental, physical and social capacities, and, second; the generally negative beliefs of the people often lead to rejection and discrimination. ${ }^{12}$ Many people with serious mental illness are challenged by the stereotypes and prejudice that result from misconceptions about mental illness. Due to which person with mental health problems are deprived of the opportunities that define a quality life: good jobs, safe housing, satisfactory health care, and affiliation with a diverse group of people. ${ }^{13}$ Stigma isolates people and delays treatment of a person with mental health problems, which in turn causes great social and economic burden. Mental illness stigma is not only limited to the public; but also found in friends and family members of the mentally ill and among mental health professions as well (nurses, doctors, psychologists, and psychiatrists) which can prevent people with mental health problems from taking advantage of opportunities that would aid them in achieving their life goals. ${ }^{14}$

\section{Prevalence of People Approaching Traditional Healers in India}

Traditional healing as a community accepted specific ritual carried out by designated figures to relieve symptoms of distress and it holds those beliefs and practices relating to disease which are the outcome of traditional cultural development and are not explicitly derived from the conceptual framework of modern medicine. ${ }^{15}$ Several studies have shown that traditional healers are consulted for mental health problems in India. Campion \& Bhugra ${ }^{16}$ surveyed to determine the experiences of religious healing in psychiatric patients in South India, observed that 45 percent of the respondents consulted traditional healers for 1 to 15 sessions 
of treatment and graduates (33 percent) were more in number among who consulted traditional healers whereas, the study of Pradhan ${ }^{17}$ identified that 35.2 percent of the respondents having mental illness visited faith healers first, before going to the psychiatrist and the study revealed that black magic (83.55 percent) was the major reason for people approaching traditional healers. The study of Chadda, ${ }^{18}$ discovered that 51 percent of the patients sought help from a traditional faith healer at some time during their illness, while a crosssectional, ${ }^{19}$ explored traditional healing practices in 201 psychiatric patients found that the majority of the respondents were suffering from depression (45 percent) approached healers (54.7 percent) before visiting psychiatrists. The study conducted in the coastal region of Karnataka by Amin \& Mohan, ${ }^{20}$ attempted to understand the various reason for which people seek the help of traditional healers and found that, 30 percent of the graduate approached healers for various reasons such as spirit possession (10 percent), jobrelated ( 50 percent), the curse of the serpent (16.66 percent), marriage issues (33.33 percent), health issues (53.33) depression (13.33 percent) and addiction (43.33 percent). As per the observation made by Rao, ${ }^{21}$ more than 90 percent of the Indians use the services of traditional healing at some point in time. Though modern medical care is available today, yet people approach traditional healers because, they share a common perception of the causes of mental illness and about the treatment modalities with their beneficiaries, which makes people more comfortable disclosing their problems than with mental health professionals.

\section{Rationale of the Study}

Poor perception of mental illness contributed to low treatment-seeking and stigmatisation of people with mental health problems. The literature from various sources has shown that poor perception towards the mentally ill is deeprooted with the rural population. Despite the development of hospitals and educational institutions, people of the coastal region of Karnataka, trait entire unnatural occurrence to the supernatural occurrence and attribute the cause of mental illness to witchcraft, punishment for past sins, and spirit possession. In order to overcome such obstacles, they approach traditional healers such as shamans, astrologers and spirit dancers to seek remedies. However, some of the practices of traditional healers are associated with potential harms. They chain the patients and abuse physically while conducting healing rituals that may lead to lacerations, fractures, and wounds while certain rituals conducted in a closed environment can cause an inadvertent carbon monoxide poisoning. Due to which the symptoms of the illness go worse and this in turn negatively affects the prognoses of treatment. Therefore, there is a need of understanding the perception of the client undergone traditional healing, which explores the views carried by the client about their illness and the effectiveness of traditional healing for their mental health problem. The result of the study may contribute to having an appropriate plan of health promotion and scaling up peoples' utilisation of mental health services, particularly among rural people with various cultures.

\section{Objectives}

1) To study the demographic profile of the patients undergone faith healing intervention for mental health problems.

2) Identify the views of the respondents about the causes of their present problem.

3) Identify the treatment received from the healers.

4) Analyse the patients' perspectives about the efficiency and outcome of healing practices performed by spirit dancers in healing mental illness.

\section{METHODS}

The present study was conducted from November 2019 to February 2020 in the Udupi district of Karnataka state. Explorative design was used to explore the views of the respondents about the cause of mental health problems and the outcome of traditional healing for their problems. Altogether 200 patients who visited traditional healers for their various mental health problems were selected based on the snowball sampling technique. In order to understand the perception and experience of the respondents, a self-prepared interview schedule was developed, which consisted of openand closed-ended questions. This tool included the beneficiaries' opinion about causes of mental illness, their awareness about the cause for the present problem, opinion about the healer and his treatment techniques, and their experience in undergoing and observed healing for mental health problems. The ethical clearance of the study was done in the presence of the institutional human ethics committee, Central University of Kerala, on $7^{\text {th }}$ December 2018. The respondents were met face to face to collect the data and the consent of the respondents was collected in writing.

\section{Statistical Analysis}

The tools were validated through face and content validity while the data was analysed based on the objectives of the study. SPSS application was used for coding and to develop a master sheet and descriptive statistics such as mean and standard deviations were used to analyse the data.

\section{RESULTS}

Demographic details of the clients undergone traditional healing for mental health problems. The findings of the demographic profile show that 27.5 percent of the patients are between the age group of 31 to 40 years, male (58 percent) patients approached traditional healers more in number while patients with secondary education who approached healers are 29 percent and people residing in the rural area represent the highest in number i.e., 44 percent. Half of the total respondents (43.1 percent) are unemployed where the patients suffering from mental illness from the past one year are 39 percent and 81 percent of the respondents never sought any treatment for their illness. 


\begin{tabular}{|c|c|c|c|}
\hline Variables & Particulars & $\begin{array}{c}\text { Frequency } \\
N=200\end{array}$ & $\begin{array}{c}\text { Percentage } \\
(\%)\end{array}$ \\
\hline \multirow{6}{*}{ Age } & $11-20$ & 16 & 8.0 \\
\hline & $21-30$ & 41 & 20.5 \\
\hline & $31-40$ & 55 & 27.5 \\
\hline & $41-50$ & 27 & 13.5 \\
\hline & $51-60$ & 24 & 12.0 \\
\hline & $61-70$ & 37 & 18.5 \\
\hline \multirow{2}{*}{ Gender } & Male & 116 & 58.0 \\
\hline & Female & 84 & 42.0 \\
\hline \multirow{7}{*}{ Education } & Illiterate & 24 & 12.0 \\
\hline & Primary & 14 & 7.0 \\
\hline & Secondary & 58 & 29.0 \\
\hline & SSLC & 43 & 21.5 \\
\hline & PUC & 41 & 20.5 \\
\hline & Graduation & 18 & 9.0 \\
\hline & Post-graduation & 2 & 1.0 \\
\hline \multirow{3}{*}{$\begin{array}{l}\text { Place of } \\
\text { residence }\end{array}$} & Rural & 88 & 44.0 \\
\hline & Urban & 50 & 25.0 \\
\hline & Semi-urban & 62 & 31.0 \\
\hline \multirow{7}{*}{ Occupation } & Unemployed & 85 & 43.1 \\
\hline & Student & 10 & 5.1 \\
\hline & Housewife & 12 & 6.1 \\
\hline & Agriculture & 21 & 10.7 \\
\hline & Self employed & 46 & 23.4 \\
\hline & $\begin{array}{l}\text { Working in the private } \\
\text { sector }\end{array}$ & 20 & 10.2 \\
\hline & $\begin{array}{l}\text { Government } \\
\text { employee }\end{array}$ & 3 & 1.5 \\
\hline \multirow{3}{*}{ Type of family } & Joint family & 21 & 10.5 \\
\hline & Nuclear family & 132 & 66.0 \\
\hline & Extended family & 47 & 23.5 \\
\hline \multirow{5}{*}{$\begin{array}{l}\text { Duration of } \\
\text { the illness }\end{array}$} & Don't know & 24 & 12.0 \\
\hline & $0-12$ months & 78 & 39.0 \\
\hline & 13 - 24 months & 48 & 24.0 \\
\hline & 25 - 36 months & 22 & 11.0 \\
\hline & 37 months and above & 28 & 14.0 \\
\hline \multirow{2}{*}{$\begin{array}{l}\text { Previous } \\
\text { treatment }\end{array}$} & Not received & 162 & 81.0 \\
\hline & Treatment received & 38 & 19.0 \\
\hline
\end{tabular}

\begin{tabular}{|c|cc|}
\hline Causes & $\begin{array}{c}\text { Frequency } \\
\mathbf{N}=\mathbf{2 0 0}\end{array}$ & $\begin{array}{c}\text { Percentage } \\
\text { (\%) }\end{array}$ \\
\hline Black magic & 51 & 25.5 \\
Curse of serpent & 44 & 22.0 \\
Past sin & 26 & 13.0 \\
Curse by god & 12 & 6.0 \\
\hline Disturbance by the spirit & 28 & 14.0 \\
\hline Effects of the soul & 19 & 9.5 \\
Physical / psychological / social problems & 6 & 3.0 \\
\hline Heredity & 3 & 1.5 \\
\hline Incidents / trauma & 3 & 1.5 \\
\hline Don't know & 8 & 4.0 \\
Total & 200 & 100 \\
\hline Table 2. Views about the Causes of the Present Problem \\
\hline
\end{tabular}

\begin{tabular}{|ccc|}
\hline Treatment Prescribed & $\begin{array}{c}\text { Frequency } \\
\mathbf{N = 2 0 0}\end{array}$ & $\begin{array}{c}\text { Percentage } \\
\text { (\%) }\end{array}$ \\
Temple visit / prayer & 37 & 18.5 \\
Offerings to god & 1 & .5 \\
Tying talisman & 0 & .0 \\
\hline Serpent worship & 75 & 37.5 \\
\hline Doctor's consultation & 1 & .5 \\
\hline Spirit expel & 40 & 20.0 \\
\hline Remove black magic & 29 & 14.5 \\
Solution for dosha (curse) & 14 & 7.0 \\
\hline Sacrifice (animal) & 3 & 1.5 \\
\hline Total & 200 & 100 \\
\hline Table 3. Treatment Received from the Healers & \\
\hline \multicolumn{2}{|l}{}
\end{tabular}

The result pertaining to the views of the respondents regarding the cause for their present problem indicates that, black magic was the major cause for mental illness among 25.5 percent of the patient, 22 percent of the respondent viewed it as the curse of the serpent and 14 percent of them felt disturbance by the spirit is the reason for their sickness. The result indicates that, the culture dominates the belief system of the people of rural areas.

In most of the cases, serpent worship (37.5 percent) is the treatment suggested for mental illness, exorcism is suggested for 20 per cent of the clients to evict demons or other spiritual entities from the client's body, and removing of black magic (14.5 percent) is another mode of treatment prescribed to the clients.

Opinion about the Outcome of Traditional Healing for Mental Health Problems

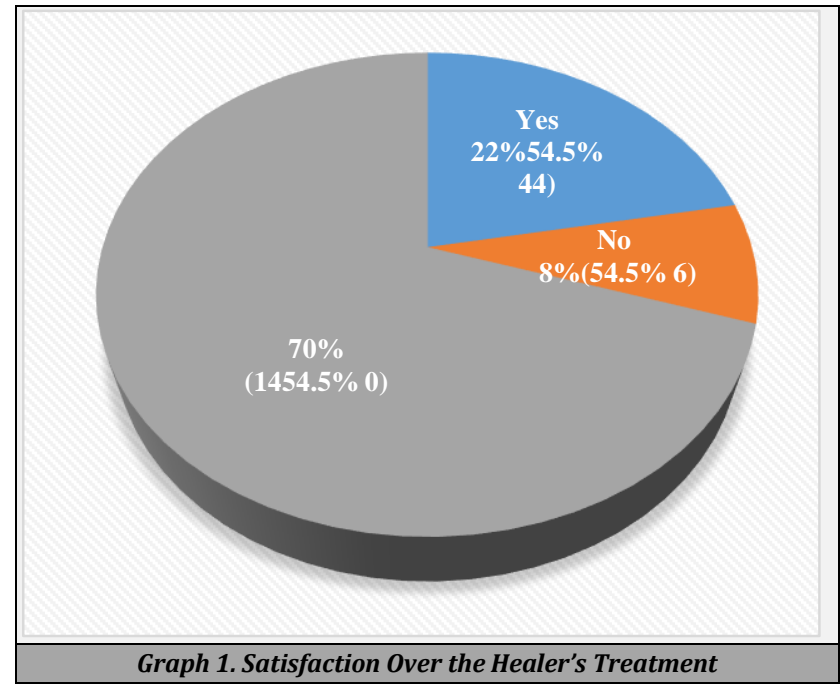

Satisfaction over the treatment received decides the better prognosis of the illness. The highest percentage of the respondents are happy to an extent (70 percent), whereas 22 percent of them are satisfied with the treatment received.

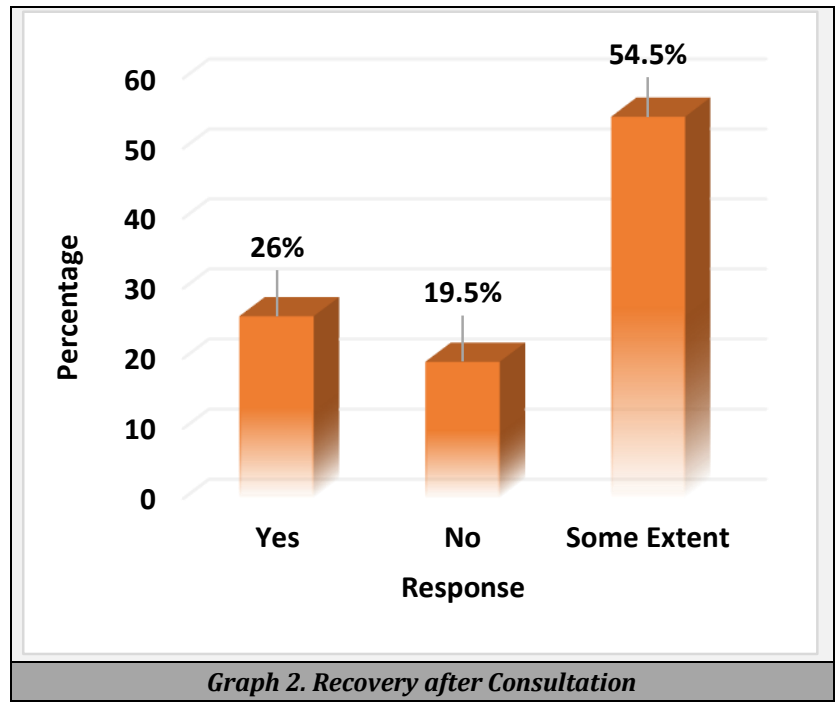

The majority of the respondents ( 54.5 percent) recovered to an extent whereas, 26 percent of the respondents completely recovered. It is estimated that 80 percent of the beneficiaries have trust in traditional healing because it is deeply rooted in their culture and religion. 


\section{DISCUSSION}

The demographic details highlight that, people from illiterate to literate and from rural to urban, approach traditional healers for their mental health care needs. In India, even a newborn baby is taken to the healers for health-related problems or to predict the future or sometimes to consult the horoscope of the child. As seen in various studies, traditional healers are the first stop for rural people to seek a solution to all sorts of problems. It is obvious that people of all the age groups fall sick, and they first consult the healers either to seek a solution or guidance.

Awareness about the causes of mental illness directs a person to seek proper mental healthcare. Nevertheless, the large population of India, especially those residing in rural areas, considers mental illness as taboo and attribute various supernatural causes to mental illness. The views carried by respondents about the causes of the present problem was almost similar to the previous study, ${ }^{22}$ which revealed that people believe in sorcery and other magico-religious practices (62 percent). There is a strong belief of ghosts / evil spirit (26 per cent), spirit possession (28.8 percent) bad deeds of the past ( 40 percent) and black magic ( 46.6 percent), attribute mental health problems to more than one of these beliefs. Curse of serpent is believed to be the cause for mental illness among rural people in the Southern part of Karnataka. In order to satisfy the serpent and seek its blessing, the majority of the healers suggest serpent worship as the treatment for a person with mental health problems. This practice not only helps the patient to overcome the illness but also aid in leading a prosperous life.

Since traditional healers considered as the person who heals the illness, people approach them in large number to seek blessings. Satisfaction on the treatment received by the respondents indicates that they have huge respect and faith over the healer, who performs ritualist tasks to cure the illness. The result of the present study is consistent with the findings of Zingela, \& Pietersen, ${ }^{23}$ where the majority of the people who consulted healers felt satisfied with the healer's intervention, however, the study of Stekelenburg 24 found that the patient's satisfaction was high after consulting the psychiatrist than visiting a traditional healer.

Recovery from mental health problems is a process of change in the prognosis of health and wellness and to be fully functional. Complete recovery is the outcome of the effective treatment provided by the therapists. The techniques used by the healers in traditional healing represent the patient's perception of illness, their needs, and their expectations. Maybe due to all factor's patients are recovered faster in traditional healing. ${ }^{25}$

\section{CONCLUSIONS}

Mental health problems contribute to the escalation of burden to the family members and the high lifetime prevalence of mental disorders exposes almost everyone directly or indirectly to many mental disorders. Recognition of mental health problems is very much essential for the mentally ill to seek professional help that could be beneficial to the health care providers for early diagnoses of the illness and to provide better mental health care. However, the cultural belief about mental health treatment is another contributing factor, which delays in help-seeking behaviour among people with mental health problems.

\section{Recommendations}

Though traditional healing practice is found worldwide, the effectiveness of the healing for mental health is not studied systematically, therefore, more evidence-based research needs to be conducted to substantiate the effectiveness of the traditional healing in treating mental health problems. It is also essential to educate the people about the positive and negative consequences of traditional healing to make them decide to choose suitable health practitioners. Further, less knowledge on mental health, fear and stigma would influence the help-seeking behaviour of people; hence, creating awareness by the mental health professional, could minimise the adverse effect of stigma and misconception. Social workers can help the patient in developing better life skills to cope with their emotional problems which could help in the faster recovery of the patient.

Data sharing statement provided by the authors is available with the full text of this article at jemds.com.

Financial or other competing interests: None.

Disclosure forms provided by the authors are available with the full text of this article at jemds.com.

My sincere thanks to all the respondents for their cooperation during the study and my research guide for sharing his knowledge and guiding me to prepare this article.

\section{REFERENCES}

[1] Srivastava K, Chatterjee K, Bhat PS. Mental health awareness: the Indian scenario. Ind Psychiatry J 2016;25(2):131-4.

[2] Ranjan JK, Asthana HS. Prevalence of mental disorders in India and other south Asian countries. Asian Journal of Epidemiology 2017;10(2):45-53.

[3] Yasmeen A. India needs to talk about mental illness. The Hindu 2016. https://www.thehindu.com/scitech/health/India-needs-to-talk-about-mentalillness/article16078825.ece

[4] Sagar R, Dandona R, Gururaj G, et al. The burden of mental disorders across the states of India: the global burden of disease study 1990-2017. The Lancet Psychiatry 2020;7(2):148-61.

[5] Snowdon J. Indian suicide data: What do they mean? Indian J Med Res 2019;150(4):315-20.

[6] Thirunavukarasu M, Thirunavukarasu P. Training and national deficit of psychiatrists in India - a critical analysis. Indian J Psychiatry 2010;52(Suppl 1):S83-8.

[7] World Health Organisation. Mental Health Atlas 2011. https://www.who.int/mental_health/evidence/atlas/pr ofiles/ind_mh_profile.pdf?ua=1

[8] Mishra A, Galhotra A. Mental healthcare act 2017: need to wait and watch. Int J Appl Basic Med Res 2018;8(2):67-70.

[9] Nair KS. Health workforce in India: opportunities and challenges. Int J Community Med Public Health 2019;6(10):4596-604. 
[10] Math SB, Gowda GS, Basavaraju V, et al. Cost estimation for the implementation of the mental healthcare act 2017. Indian J Psychiatry 2019;61(Suppl 4):S650-S9.

[11] Kishore J, Gupta A, Jiloha RC, et al. Myths, beliefs and perceptions about mental disorders and health-seeking behavior in Delhi, India. Indian J Psychiatry 2011;53(4):324-9.

[12] Angermeyer MC, Dietrich S. Public beliefs about and attitudes towards people with mental illness: a review of population studies. Acta Psychiatr Scand 2006;113(3):163-79.

[13] Corrigan PW, Watson AC. Understanding the impact of stigma on people with mental illness. World Psychiatry 2002;1(1):16-20.

[14] Shrivastava A, Johnston M, Bureau Y. Stigma of mental illness-1: clinical reflections. Mens Sana Monogr 2012;10(1):70-84.

[15] Sarkar S, Seshadri H. Dealing with requests for faith healing treatment. Indian J Med Ethics 2015;12(4):235-7.

[16] Campion J, Bhugra D. Experiences of religious healing in psychiatric patients in south India. Soc Psychiatry Psychiatr Epidemiol 1997;32(4):215-21.

[17] Pradhan SN, Sharma SC, Malla DP, et al. A study of help seeking behavior of psychiatric patients. Journal of Kathmandu Medical College 2014;2(1):21-4.
[18] Mishra N, Nagpal SS, Chadda RK, et al. Help-seeking behavior of patients with mental health problems visiting a tertiary care center in north India. Indian J Psychiatry 2011;53(3):234-8.

[19] Roberts T, Shidhaye R, Patel V, et al. Health care use and treatment-seeking for depression symptoms in rural India: an exploratory cross-sectional analysis. BMC Health Serv Res 2020;20(1):287.

[20] Amin P, Mohan AK. Knowledge of indigenous healers on mental health problems. J Critical Reviews 2020;7(14):2403-10.

[21] Rao G. Faith Healing [dissertation]. Mangalore University 1999: p. 160.

[22] Rathinavel I, Prashanth NR, Kasthuri P, et al. Why do mentally ill patients seek religious places for treatment? Indian J Psychiatry 2010;52(3):280-1.

[23] Zingela Z, van Wyk S, Pietersen J. Use of traditional and alternative healers by psychiatric patients: a descriptive study in urban South Africa. Transcult Psychiatry 2019;56(1):146-66.

[24] Stekelenburg J, Jager BE, Kolk PR, et al. Health care seeking behaviour and utilisation of traditional healers in Kalabo, Zambia. Health Policy 2005;71(1):67-81.

[25] Pinkoane MG, Greeff M, Williams MJ. The patient relationship and therapeutic techniques of the South Sotho traditional healer. Curationis 2005;28(4):20-30. 